\title{
OS PAYAYÁ DE JACOBINA: RESISTÊNCIAS E NEGOCIAÇÕES NOS SERTÕES DA BAHIA (SÉCULOS XVI-XVII)
}

\author{
THE PAYAYÁ FROM JACOBINA: RESISTANCE AND NEGOTIATION IN THE \\ BAHIA'S HINTERLANDS (16 ${ }^{\mathrm{TH}}-17^{\mathrm{TH}}$ CENTURIES)
}

\author{
Fabricio Lyrio Santos* \\ Solon Natalício Araújo dos Santos**
}

\begin{abstract}
RESUMO
Este artigo busca retratar parte da trajetória histórica dos Payayá, povo indígena originário do Sertão das Jacobinas, no interior da Babia, região entendida enquanto espaço construído historicamente a partir da mobilidade, do contato e das trocas entre os diversos grupos indígenas e colonizadores. A partir da segunda metade do século XVI até meados do XVII, durante o processo de conquista e colonização, o grupo indígena Payayá ganha relevo na documentação, ora como inimigo, ora como aliado do projeto colonizador. Este e diversos outros povos indigenas precederam a chegada e o avanço dos colonizadores em busca de mão de obra, riquezas e terras na região. Tendo por base documentos administrativos, relatos de missionários e crônicas, pretende-se colocar em relevo os principais aspectos identitários deste grupo indígena e seu acentuado protagonismo.
\end{abstract}

PALAVRAS-CHAVE: Índios. Payayá. Jacobina. Sertões.

\begin{abstract}
This paper looks at the historical trajectory of the native Indians of "Sertão das Jacobinas" [Jacobinas' Backlands], in Babia, known as the "Payaya'. In the colonial period, this region has been historically constructed by the mobility, intense contact and cultural changes between indigenous and colonial groups. By the second half of $16^{\text {th }}$ century for the first of the next, along colonization and conquest process, the "Payaya" becomes one of the most important group either as an ally or as an enemy of the colonial powers and agents (such as governors, missionaries, settlers, planters etc.). Based upon official documents, religious writings and laymen's relations, this article intends to highlight the Payayás' identity and protagonism.
\end{abstract}

KEYWORDS: Indians. Payayá. Jacobina. Backlands. Bahia.

\footnotetext{
* Professor da Universidade Federal do Recôncavo da Bahia (UFRB) e do Mestrado em História Regional e Local da Universidade do Estado da Bahia (UNEB). Doutor em História pela Universidade Federal da Bahia (UFBa). E-mail: fabriciolyrio@gmail.com

** Professor da Secretaria de Educação do Estado da Bahia (SEC-BA) e da Secretaria Municipal de Educação de Mulungu do Morro - BA. Mestre em História pela Universidade Federal da Bahia (UFBa). E-mail: s_natalicio@yahoo.com.br
} 


\section{INTRODUÇÃO}

Nas palavras do famoso escritor jesuíta André João Antonil (pseudônimo de João Antônio Andreoni), os sertões da Bahia se estendiam

[...] até a barra do rio São Francisco, oitenta léguas por costa; e indo para o rio acima, até a barra que chamam de Água Grande, fica distante a Bahia da dita barra cento e quinze léguas; de Centocê, cento e trinta léguas; de Rodelas por dentro, oitenta léguas; das Jacobinas, noventa; e do Tucano, cinqüenta (ANTONIL, 1982, p. 199).

Neste vasto sertão, diversos foram os povos e etnias indígenas que precederam a chegada e o avanço dos colonizadores em busca de mão de obra, riquezas e terras (DANTAS; SAMPAIO; CARVALHO, 1992). A maioria desses povos pouco aparece na documentação colonial, tendo sido silenciada sua existência. Outros, em contraste, aparecem de forma reiterada, ora como inimigos, ora como aliados do projeto colonizador. Este é o caso o grupo indígena Payayá, habitante dos sertões das Jacobinas, região devassada pelos colonizadores entre fins do século XVI e a primeira metade do XVII (SANTOS, S., 2011).

Do termo tupi Ya-Qua-Apina, que significa "jazida de cascalho limpo" ou "terreno impróprio para a lavoura e revestido de mato baixo, geralmente cerrado e espinhoso", provavelmente derivou o topônimo Jacobina. Outra possibilidade é a de que tenha derivado de Yacuy (jacuíba) e Bina (desfolhoada), uma "espécie de árvore que perde as folhas por ocasião das secas". Jacoabina ou Jacuabina também pode significar "campo aberto" ou "campo vasto sem elevação" (FALCÃO, 2001, p. 349350).

A Jacobina da colonização lusitana correspondia a um "terreno vastíssimo composto de serras altíssimas, e extensas em partes, quando em partes, tem planícies imensas, e terras menos altas" (VILHENA, 1968, p. 561). A região, segundo Afonso Costa, tornou-se conceito de "tudo quanto se contasse fóra do recôncavo e do litoral", ou seja, "um nome opulentado de grandezas e de misérias" (COSTA, 1918, p. 252).

Neste artigo pretendemos retratar e analisar parte da trajetória histórica e do protagonismo dos índios Payayá da região de Jacobina, entendida enquanto espaço construído historicamente a partir da mobilidade, do contato e das trocas entre os diversos grupos indígenas durante o processo de conquista e colonização lusitana, a partir da segunda metade do século XVI a meados do XVII. 


\section{A TAPUYRAMA DOS PAYAYÁ}

O fascínio pelo sertão despertou o imaginário dos colonos desbravadores da Bahia, ambiciosos por ouro e riquezas minerais, mas também receosos dos bárbaros "tapuias". O termo "sertão", como é sabido, consiste em uma representação bastante disseminada na sociedade colonial, construída por viajantes, missionários e cronistas para explicar um espaço considerado vazio, indomado e selvagem (MIGUEL; NEVES, 2007, p. 13-14). Espaço do "outro" por excelênica, o "gentio bárbaro", o "tapuia”, em oposição ao litoral, espaço social ocupado pelos colonos, com seus trabalhadores escravizados e indígenas supostamente "mansos", isto é, aldeados ou escravizados. Por conseguinte, o sertão, enquanto território interior desconhecido ou "incógnito" onde se refugiavam "as tribus tapuyas expellidas do litoral”, poderia também ser conhecido como “Tapuyrama”, cuja tradução em tupi significa "região dos tapuias ou dos bárbaros" (SAMPAIO, 1901, p. 50).

Em seu Tratado Descritivo do Brasil, de 1587, o senhor de engenho Gabriel Soares de Sousa afirma: "são os tapuias contrários de todas as outras nações do gentio, por terem guerra com eles ao tempo que viviam junto do mar, de onde por força de armas foram lançados” (SOUSA, 2001, p. 261). Nas palavras do cronista Frei Vicente do Salvador, "os mais barbaros se chamão in genere Tapuhias, dos quaes ha muitas castas de diversos nomes, diversas lingoas, e inimigos huns dos outros" (SALVADOR, 1889, p. 24). Já o escritor jesuíta Simão de Vasconcelos, em sua Crônica da Companhia de Jesus no Brasil, de 1663, assegura que as nações "Tapuias” compreendiam quase cem línguas distintas, "e por conseguinte outras tantas espécies: a saber, Aimorés, Potentus, Guaitacás, Guaramonis, Goaregoarês, Jeçaruçus, Amanipaqués, Paieás: seria cansar contar todas” (VASCONCELOS, 1977, p. $110)$.

Nota-se, nesta descrição, a presença dos "Paieás", provavelmente os mesmos "Payayá" habitantes dos sertões das Jacobinas que aparecem na documentação dos séculos XVI e XVII juntamente com outros tantos povos, identificados como Sapoiás, Tocós, Moritises, Maracás, Secaquerinhens, Cacherinhens, Caimbés, Pankararu, Ocren, Oris, Tamaquins, Araquenas, Anaiós e Topins. Sua inclusão quase indiferenciada entre "outras tantas espécies de tapuias" revela o tratamento indistinto que a documentação colonial tendia a estabelecer para os povos que não eram falantes do Tupi.

Retornando a Gabriel Soares de Sousa, nota-se que ele descreve um grupo indígena identificado como "Papanases". Segundo sua narrativa, este povo teria vivido ao longo do mar entre as capitanias de Porto Seguro e Espírito Santo, sendo expulso dali pelos Tupiniquins e Goitacases após uma "tão cruel guerra que os fizeram sair para o sertão, onde agora têm sua vivenda". Segundo o mesmo cronista, apesar da inimizade, tanto os Tupiniquins quanto os Goitacases entendiam a 
linguagem daquele grupo, “ainda que mal”. Em relação às características étnicas e culturais, detalha o cronista:

Este gentio dorme no chão, sobre folhas, como os goitacases; também não se ocupa em grandes lavouras; mantêm-se estes selvagens de caça e peixe do rio, que matam; os quais são grandes flecheiros e pelejam com arcos e flechas, andam nus como o mais gentio, não consentem cabelos nenhuns no corpo, senão os da cabeça, pintamse e enfeitam-se com penas de cores dos pássaros; cantam e bailam; têm muitas gentilidades, das que usam os tupinambás; mas, entre si, têm um costume que não é tão bárbaro, como todos os outros que todo o gentio costuma, que é, se um índio destes mata outro da mesma geração em alguma briga, ou por desastre, são obrigados os parentes do matador a entregá-lo aos parentes do morto, que logo o afogam e o enterram, estando uns e outros presentes, e todos neste ajuntamento fazem grande pranto, comendo e bebendo todos juntos por muitos dias, e assim ficam todos amigos. e sendo o caso que o matador fuja, de maneira que os parentes não o possam tomar, lhe tomam um filho ou filha, se o tem, ou irmão, e se não tem nem um nem outro, entregam pelo matador o parente mais chegado, ao qual não matam, mas fica cativo do mais próximo parente do morto, e com isso ficam todos contentes e amigos como o eram antes do acontecimento do morto. (SOUSA, 2001, p. 76)

Mais de um século depois, a mesma informação presente no final do trecho citado acima aparece na História da América Portuguesa, de Sebastião da Rocha Pitta, que afirma:

Porém entre eles a nação dos gentios que chamam Papanases, mostrava alguma sombra de justiça ou de razão, posto que incivil e bárbaramente praticada; porque, se algum tirava a vida a outro por qualquer pendência ou desastre, obrigavam aos parentes do matador a entrega-lo aos da família do morto, que o afogavam e metiam debaixo da terra logo, em presença de um e outros; e no caso que se houvesse ausentado, e o não pudessem os parentes descobrir para o entregarem, lhe tomavam um filho varão, ou fêmea, e não os tendo lançavam mão do parente mais próximo em, grau, ao qual não matavam, mas ficava escravo do mais propínquo em sangue ao morto, e desta sorte todos contentes se faziam amigos, sem maquinarem outro género de vingança, evitando muitas mortes com esta forma de castigo e satisfação (PITTA, 1965, p. 37).

Ao lado das referências de Gabriel Soares de Sousa, Sebastião da Rocha Pitta e Simão de Vasconcelos aos índios "Papanazes" e "Paieás", as principais fontes acerca das características culturais e manifestações simbólicas dos Payayá foram recolhidas pelos missionários jesuítas em meados do século XVII. O Sexennium Litterarum 1651-1657 constitui a mais detalhada descrição dos Payayá, contatados em uma entrada de 1656 que visava chegar aos Amoipiras, povo de língua Tupi habitante do sertão da Bahia (Cf. LEITE, 2000, p. 271-278).

Nesse relato, os Payayá são apresentados como um grupo muito submisso aos seus pajés. Não adoravam ídolos nem divindidades, possuindo apenas "uma semelhança de idolatria, no que chamam seu deus Eraquizã". Não estavam sujeitos a lei ou rei. Eram um povo tranquilo e simples, que gastava o tempo em comer, beber e se divertir. Praticavam a antropofagia entre os membros do próprio grupo, pois, segundo o relato, quando um doente era desenganado pelos pajés, tinha a morte acelerada por seus parentes que, em um gesto de compaixão, se alimentavam de sua carne. Há também uma 
referência ao ritual antropofágico praticado contra os inimigos, à semelhança do que praticavam os grupos Tupi, segundo os relatos coloniais (LEITE, 2000, p. 274-275).

Seriam os "Paieás" de Simão de Vasconcelos e os "Papanases" de Gabriel Soares de Sousa e Sebastião da Rocha Pitta os mesmos "Payayá" do sertão das Jacobinas, contatados pelos jesuítas no século XVII? A hipótese não é descabida, haja vista o citado deslocamento daqueles povos para o sertão, o que daria um significado mais amplo para o posterior deslocamento dos Payayá para a região de Camamu, no século XVII. Este "descimento" tem sido visto como uma imposição externa, a serviço dos interesses dos missionários e colonos (LEITE, 2000, p. 280). No entanto, talvez ele tenha se dado também em função do interesse indígena, configurando um retorno para o litoral, numa tentativa de ocupação de uma região com características semelhantes àquelas em que viviam seus antepassados.

Antes deste deslocamento, os Payayá ocupavam as terras mais férteis do Sertão das Jacobinas, o que decerto atraiu os colonos para aquela área. Eles possivelmente cultivavam diversos gêneros alimentícios como o feijão, milho, amendoim e abóbora (vegetais que exigem ciclos de curta duração de três a cinco meses entre o plantio e a colheita), a mandioca e o aipim (ciclos de longa duração, de um a três anos), a batata-doce (ciclo perene) e o cará ou inhame (ciclo médio), além de caçarem veados, porcos do mato, cascavéis, surucucus e coletarem umbu, mandacaru, xiquexique e mel de mandassaia (OTT, 1993).

Carlos Ott defende que os Payayá acrescentaram também o peixe à sua alimentação mediante o costume de se deslocarem até a região do recôncavo baiano para coletarem frutos de beira mar, praticarem rituais e pescarem, principalmente, a tainha, que, depois de salgada e triturada, gerava uma farinha de peixe (também chamada de farinha de guerra). Esta, quando misturada com a farinha de mandioca, tornava-se essencial para a subsistência no sertão, principalmente durante os períodos de secas prolongadas e de guerras, posto que este alimento durava meses (cf. GÂNDAVO, 1980, p. 48; OTT, 1993, p. 35-46; OTT, 1944, p. 20).

Com base em achados arqueológicos encontrados na superfície da área cultural atribuída aos falantes do Kariri, os Payayá podem ser identificados como um povo que praticava a caça, a coleta e a agricultura, fabricava instrumentos de pedra e, possivelmente, cerâmica, embora possuísse características seminômades. Carlos Ott levanta a hipótese de que grupos Tupi tivesem relações comerciais com os da família Kariri, adquirindo deles machadinhos de nefrite e jadeite, e tembetás de quartzo verde em troca de produtos como farinha de peixe e cerâmica (OTT, 1993, p. 253-254). Um indício a este respeito pode ser visto em um documento escrito no início do século XVIII pelo sertanista Pedro Barbosa Leal. Ele afirma que os índios das Jacobinas mineravam pedras verdes "para fazer os seus batoques que commerceam com outros" (LEAL, 1978, p. 69-83). 
Estas trocas comerciais explicariam a presença de urnas funerárias e recipientes cerâmicos quadrangulares (assadores) vinculados à tradição ceramista Tupi, datados de 1300 d.C., na área cultural atribuída aos falantes do Kariri, a saber, em Santa Úrsula e Barra dos Negros, no atual município de Morro do Chapéu, Bahia (Figuras 1 a 3).

Figura 1 - Urna funerária Tupi.

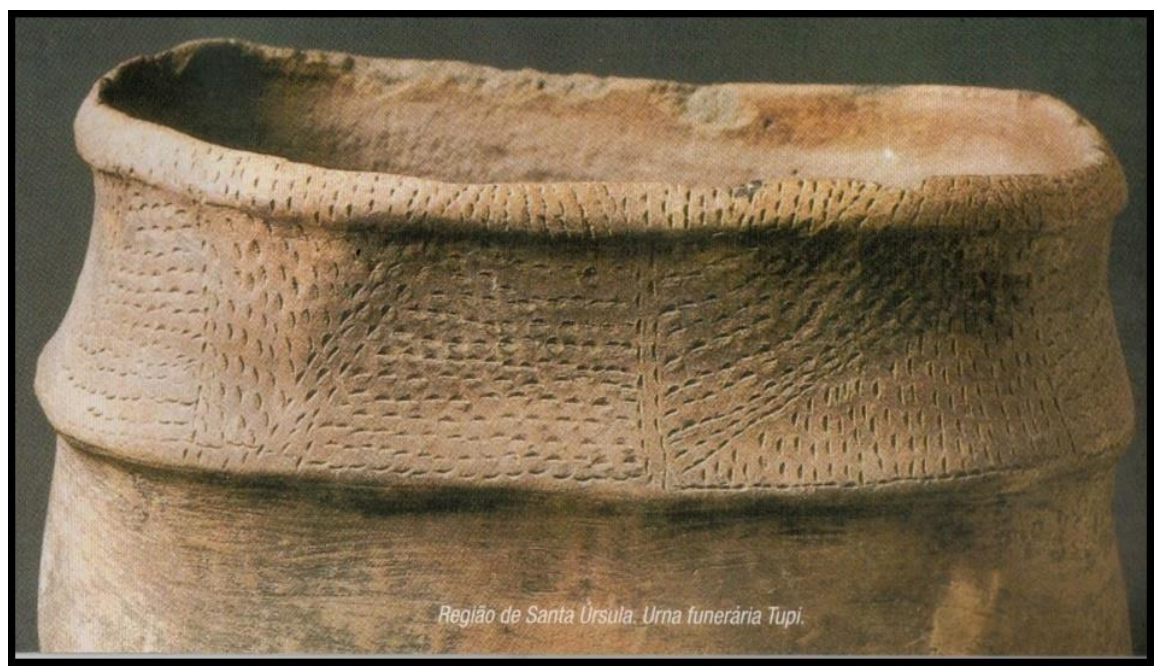

Fonte: ETCHEVARNE, 2015, p. 12.

Figura 2 - Urna funerária da tradição Tupi.

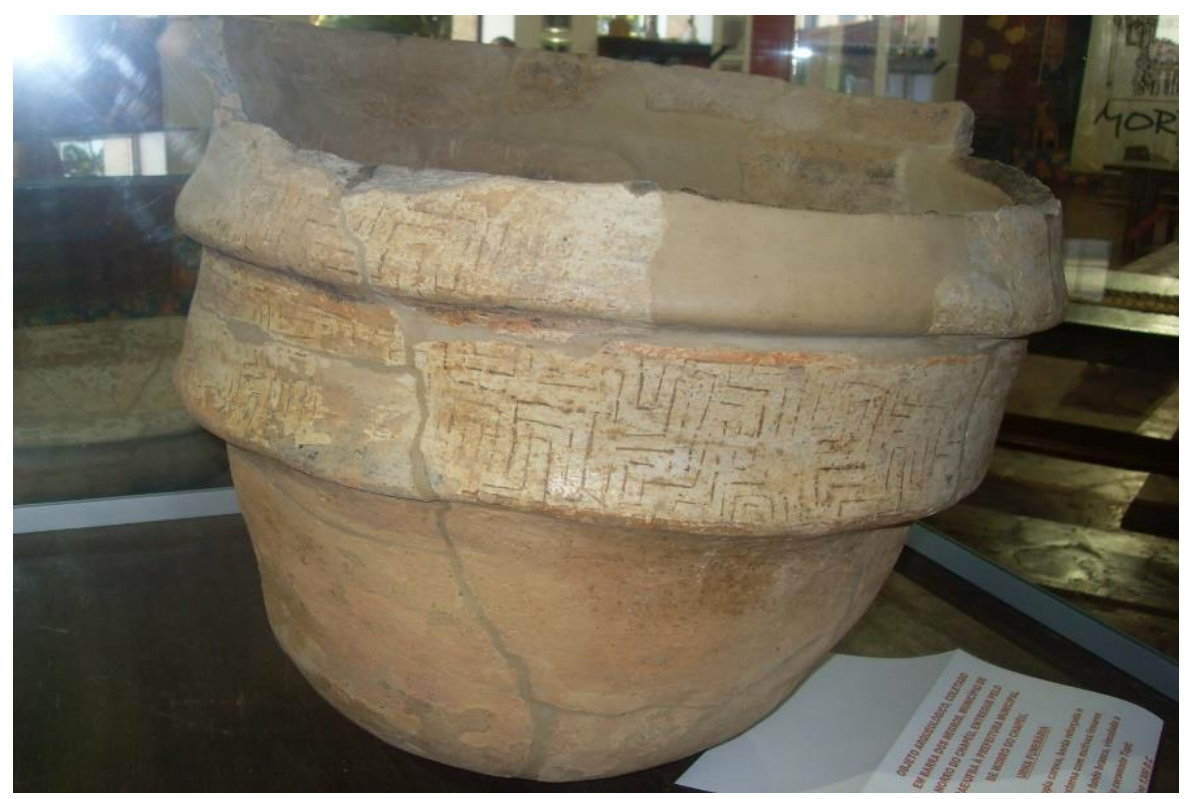

Fonte: Acervo Arqueológico da Casa da Arte de Morro do Chapéu

Reprodução fotográfica: Solon Santos. Data: 10/02/2009 
Figura 3 - Recipiente cerâmico (assador) da tradição Tupi

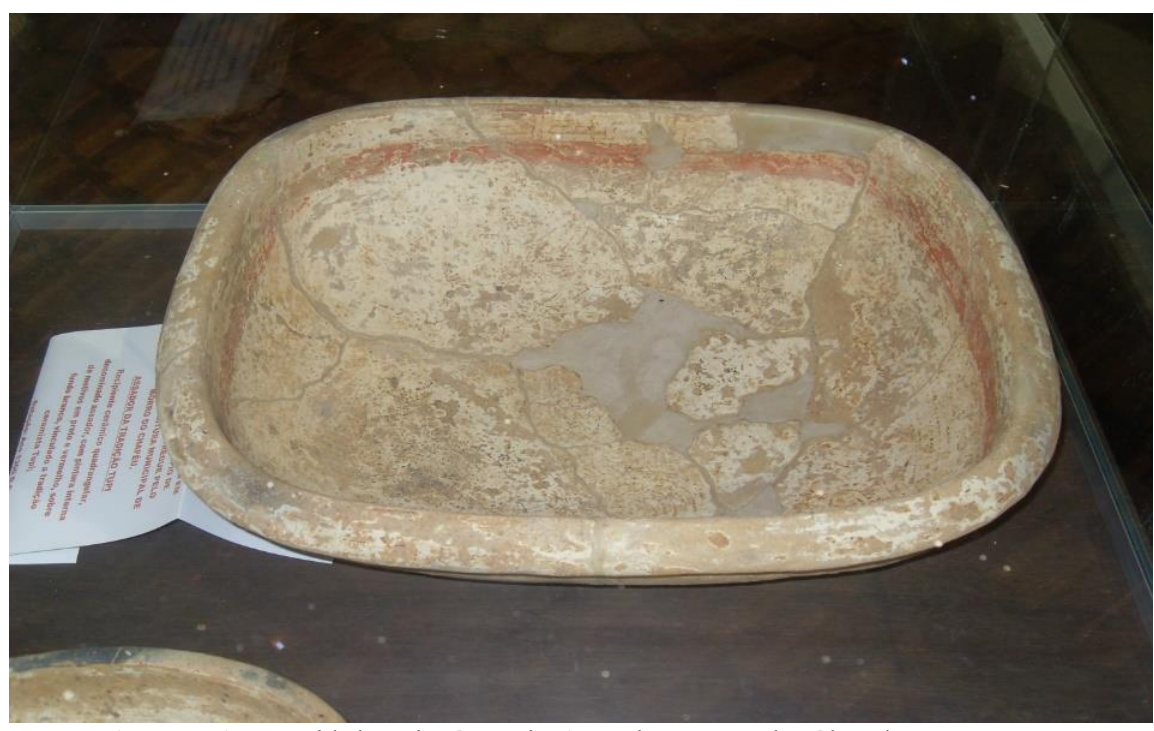

Fonte: Acervo Arqueológico da Casa da Arte de Morro do Chapéu

Reprodução fotográfica: Solon Santos. Data: 10/02/2009.

\section{AINDA QUE AMIGOS, BÁRBAROS}

O período mais intenso das relações de contato e do processo de aldeamento dos povos indígenas dos sertões da Bahia coincide com a fase mais rígida da chamada Guerra dos Bárbaros. Diante do complexo quadro de combates e alianças, os Payayá tiveram uma ação de destaque na etapa que ficou conhecida como "Guerras no Recôncavo" (1651-1673). A dependência dos portugueses em relação aos índios mostrou-se crítica nos episódios envolvendo os ataques dos “Tapuias” às plantações e engenhos do recôncavo, redimensionando os processos de resistências e negociações (cf. PUNTONI, 2002; NEVES, 2008, p. 38-76; MAGALHÃES, 2015, p. 100-64).

Em 1657, o governador Francisco Barreto encarregou o ajudante Luis Alvares de realização de uma jornada para convencer os Payayá de Jacobina a se deslocarem de suas aldeias para as dos Tapuias, na Serra do Orobó. Os Payayá viviam em cerca de 15 povoações e eram considerados amigos, ou seja, aliados dos portugueses. O objetivo deste deslocamento - que envolveria toda a população aldeada era criar uma barreira étnica no Orobó a fim de proteger o recôncavo das incursões dos demais Tapuias. É interessante notar que, por sua condição de aliados, os Payayá não aparecem no documento como "Tapuias". Além disso, o deslocamento deveria ser feito por meio da persuasão e do tratamento amigável. Em relação aos argumentos a serem usados para persuadi-los, destacam-se como principais: a inimizade entre os Payayá e os "Tapuyas", que atacavam o recôncavo; e a posse anterior do território do Orobó por parte daqueles. Ou seja, o governador pretendia que as negociações com os Payayá 
fossem baseadas, inicialmente, em interesses comuns - o combate aos Tapuias e a retomada da Serra do Orobó (DOCUMENTOS HISTÓRICOS, 4, p. 57-59; PUNTONI, 2002, p. 100).

Como a expedição de Luis Alvares demorou a dar notícias, o governador resolveu enviar em seu auxílio o capitão Bartolomeu Aires com quatro companhias (PUNTONI, 2002, p. 100-1). O objetivo principal era iniciar a guerra aos Tapuias, mas o regimento contendo as ordens do governador, datado de 31 de janeiro de 1658, determinava também que ele tentasse contactar a expedição de Luis Alvares ou encontrar diretamente os Payayá. Diversos parágrafos fazem referência aos Payayá, com destaque para os itens 10 e 11, que apresentam os argumentos a serem usados perante os principais daquela etnia para persuadi-los a acompanhá-lo de volta até o Recôncavo ou à Serra do Orobó (DOCUMENTOS HISTÓRICOS, 4, p. 64-75).

Assim que encontrasse os Payayá, Aires deveria se dirigir aos seus principais, tratando-os com "toda a honra e bom tratamento, que no seu estylo Barbaro parecer maior". Na argumentação, o capitão deveria enfatizar o interesse comum em desbaratar os Tapuias, inimigos comuns, e destruir suas aldeias. Quanto ao deslocamento, no entanto, o governador sugeria que os índios fossem persuadidos a estabelecer suas aldeias junto ao rio Paraguaçu, próximo ao forte que ele próprio havia mandado construir, para melhor defesa da região e dos engenhos e fazendas do Recôncavo. No entanto, se eles insistissem em se deslocar somente até o Orobó, seriam advertidos da obrigação de sustentar os soldados designados para sua defesa (DOCUMENTOS HISTÓRICOS, 4, p. 68-70).

O capitão deveria reuni-los em um local seguro, construir uma paliçada para protegê-los e deixar a aldeia ou fortificação sob o encargo de um cabo de sua confiança, com vinte e cinco soldados e bastante munição. O cabo deveria conservá-los em estreita obediência, agindo sempre "com todo o bom modo e prudencia que pede a communicação de uns homens barbaros para os ter sempre conformes, e inclinados". O governador adverte, ainda, que o referido cabo tivesse a máxima cautela e desconfiança com os Tapuias aliados dos portugueses e até mesmo com os Payayá, "por serem (ainda que amigos) bárbaros" (DOCUMENTOS HISTÓRICOS, 4, p. 71).

Nota-se que os Payayá não são igualados aos demais povos “Tapuyas", sendo tratados de forma individualizada. De fato, o regimento de Bartolomeu Aires fala em "Tapuyas amigos" e "Tapuyas inimigos", diferenciando ambos os grupos dos Payayá. Além disso, o tratamento que thes é oferecido vai além do simples recrutamento para a guerra. A ideia era persuadi-los a se deslocar para uma área próxima ao recôncavo, devendo levar consigo suas mulheres e crianças, pertences e mantimentos. Os principais argumentos em favor deste deslocamento priorizavam, como forma de persuasão, os interesses dos índios, reconhecendo sua capacidade de escolha e, portanto, de recusa:

Feita esta pratica os persuadirá, que escolham os melhores arcos que trouxerem para com elles ir Bartholomeu Aires conquistar as Aldeias dos Tapuyas inimigos que estiverem na mesma Serra do Orobó, ou mais adiante na do Outinga: e os mais com suas mulheres, e familias desçam a alojar-se, e formar Aldeias junto ao Rio 
Paraguassú donde temos a nossa casa forte; por ser parte muito mais capaz de roças, e terra melhor para todo o genero de legumes, o Rio muito farto, os mattos muito cheios de caça, e elles ficarem mais vizinhos a nós, mais longe de seus contrarios, e já seguros com a casa forte, para dalli (vivendo elles sempre quietos) sairem as nossas tropas, e as suas a desinquietar os Tapuyas contrarios, e fazer-lhes guerra dentro as Aldeias mais apartadas. (DOCUMENTOS HISTÓRICOS, 4, p. 69).

Obviamente, dadas as relações de poder inerentes à condição dos índios e dos portugueses, não era esperado pelo governador que os Payayá recusassem sua proposta. No entanto, essa era uma hipótese prevista também no regimento:

Mas se comtudo o amor que (os) Payayases têm á Serra do Orobó, por haver sido
sua, os não deixar persuadir a que desçam para a casa forte, e se resolvam a ficar na
Serra do Orobó: o Capitão Bartholomeu Aires lhes dirá que a razão de tambem lhe
não convir ficar na Serra do Orobó, é a difficuldade de se levar lá a farinha para
sustento dos Soldados, que alli hão de ficar em sua guarda. E que emquanto elles
não plantam tantas roças, que se possam lá sustentar os Soldados sem ir farinha
desta praça, serão os mesmos Principaes dos Payayases obrigados a mandar fabricar
pelos Tapuyas a casa forte, todo o mantimento que for necessario para conservação
dos Soldados, que lá ficarem em sua guarda; e a partir com elles das caças, que
tiverem para seu sustento; pois ficam tão longe da Cidade, e faltos de tudo, só pelos
defender com as armas dos Tapuyas seus inimigos (DOCUMENTOS
HISTÓRICOS, 4, p. 70).

Nota-se que, a despeito de uma suposta correlação de forças favorável aos portugueses, há uma constante preocupação em persuadir os índios, adotando argumentos que colocavam os colonos como aliados dos Payayás no enfrentamento do inimigo comum. Apesar de tudo, as duas expedições enviadas a Jacobina não lograram o sucesso esperado. Os Payayá, aparentemente, não se deixaram convencer pelos argumentos apresentados pelas tropas enviados do recôncavo e permaneceram em suas terras.

Alguns anos mais tarde, em 1669, o novo governador Alexandre de Sousa Freire narrou perante o Tribunal da Relação da Bahia os episódios envolvendo o desfecho das jornadas enviadas ao sertão das Jacobinas por seu antecessor. Buscando sustentar argumentos contrários à política de cooptação dos grupos indígenas seguida até então pelos portugueses, Sousa Freire faz referência a um episódio em que os Payayá surgem como protagonistas (DOCUMENTOS HISTÓRICOS, 5, p. 20716; PUNTONI, 2002, p. 104-105).

$\mathrm{Na}$ sequência da expedição de Bartolomeu Aires foi montada uma terceira, chefiada pelo paulista Domingos Barbosa Calheiros, que chegou à Bahia no dia 14 de outubro de 1658. Ele partiu ao encontro dos Payayá, supostamente contatados e pacificados pelas expedições que lhe antecederam. Ao encontrá-los, no entanto, acabou sendo vítima de um terrível embuste, pois os Payayá, pretextando levar suas tropas até as aldeias dos Tapuias inimigos dos portugueses, guiaram-nas durante mais de sessenta dias pelo sertão sem chegar a lugar algum. As tropas, cansadas e famintas, tornaram-se presas 
fáceis para os "traiçoeiros" Payayá, que supostamente mataram e comeram vários dos seus remanescentes (DOCUMENTOS HISTÓRICOS, 5, p. 211-2; PUNTONI, 2002, p. 104).

De acordo com o governador Alexandre de Sousa Freire, na proposta apresentada ao Tribunal da Relação da Bahia, os gentios bárbaros deveriam ser tratados com o máximo rigor, mandando que os que se recusassem a cooperar fossem degolados e os que fossem aprisionados, declarados cativos. As aldeias inimigas deveriam ser completamente destruídas e suas terras divididas entre os vencedores, "para assim poderem ficar livres os moradores, e sossegadas as hostilidades do Gentio". Os membros do Tribunal da Relação ponderaram que a resolução tomada pelo governador estava de acordo com as ordens régias e, diante das razões apresentadas, "pareceu a todos, conformemente, que a guerra era justa”. Quanto aos índios aliados que tivessem passado para o lado dos inimigos, estes deveriam ser tratados como rebeldes e traidores a fim de que pudessem servir de exemplo para os demais. Talvez esta última observação tivesse em mira principalmente os Payayá (DOCUMENTOS HISTÓRICOS, 5, p. 215-216).

De fato, o episódio envolvendo os Payayá foi usado pelo governador como prova da sua "natural perfídia, e inconstância". Sousa Freire argumenta que a política de alianças levaria sempre os portugueses ao fracasso e que a única maneira de pacificar os índios era por meio do castigo e da guerra, como mostrava a experiência na Bahia e os notórios exemplos em toda a América (DOCUMENTOS HISTÓRICOS, 5, p. 213).

Desse relato do governador resultou o assento que decretou a guerra justa contra os Payaya e demais povos do sertão. Sousa Freire recorreu à convocação dos sertanistas paulistas, sob o comando de Estavão Ribeiro Baião Parente, para a chefia das expedições. Estes, no entanto, não chegaram durante o governo de Alexandre de Sousa Freire, entando em ação apenas no governo de seu sucessor, Afonso Furtado de Castro do Rio de Mendonça, o visconde de Barbacena (Cf. SANTOS, S., 2011, p. 169-181).

\section{A CONQUISTA DOS PAYAYÁ NO SERTÃo PELOS JESUÍTAS}

Concomitante às expedições lideradas pelos paulistas (1671-1675), o padre Antonio de Oliveira, da Companhia de Jesus, conseguiu fundar uma aldeia entre os Payayá no sertão e os assistiu durante três anos, juntamente com o padre Francisco de Avelar (LEITE, 2000, p. 279). Como referido anteriormente, os religiosos da Companhia de Jesus foram os primeiros missionários a manter contato com os povos indígenas no Sertão das Jacobinas durante os dois primeiros séculos da colonização, atuando como capelães nas expedições organizadas pelos colonos ou pelas autoridades locais em busca de ouro, prata e "gente do sertão mais capaz", isto é, índios propícios à conversão e ao trabalho nas 
plantações dos colonos (LEITE, 2000, p. 173-177; LEITE, 1940, p. 154-159; POMPA, 2003, p. 316; VAINFAS, 1995, p. 145).

Devido às investidas dos holandeses na costa e ameaças francesas, as entradas se tornaram rarefeitas entre fins do século XVI e início do seguinte. Só a partir de meados do século XVII, após a expulsão dos holandeses instalados no Nordeste açucareiro, o projeto colonial passou por um processo de interiorização, penetrando os sertões por meio da ocupação e apropriação das terras, da expansão da pecuária, das ações de missionários, das expedições em busca de metais, pedras preciosas e negros da terra. Na capitania da Bahia, este processo de interiorização da expansão colonial tinha como grande objetivo avançar até o rio São Francisco. Entre as décadas de 1630 e 1650, os Adornos do Paraguaçu, os d'Ávila da Casa da Torre de Tatuapara, Antônio Guedes de Brito e João Peixoto Viegas acumularam um domínio de muitas dezenas de propriedades rurais.

A empresa missionária, sintonizada com a política de interiorização do projeto colonial promovida pelas autoridades e colonos, foi incentivada, principalmente, com a finalidade de "descer" os chamados "tapuias" para o litoral ou fixá-los em aldeamentos no meio do sertão para serem catequizados e servirem de mão de obra ou soldados para as campanhas militares (PUNTONI, 2002, p. 53-55). Os religiosos, obviamente, além de solidários ao projeto colonial, buscavam cumprir sua missão, visando a conversão dos gentios e o triunfo da catequese (Cf. SANTOS, F., 2014).

Entretanto, os sesmeiros João Peixoto Viegas e Antonio Guedes de Brito, por alcançarem o favor do governador Afonso Furtado Rio de Mendonça (1671-1675), pretendiam remover as aldeias dos Payayá para que servissem de defesa às suas terras contra outros grupos indígenas. Em 1675, o governador concedeu a Peixoto Viegas, por meio de um alvará, a administração dos ditos índios em reconhecimento dos serviços por ele prestados em prol da colonização do recôncavo (SILVA, 1925, p. 231-232). Esta concessão fragilizava a posição dos jesuítas que almejavam garantir a administração de todos os índios aldeados na colônia nos termos presentes nas Leis de 1596 e 1609, embora a Lei de 1611 prescrevesse a nomeação de capitães leigos para as aldeias (Cf. SANTOS, F., 2014, p. 59-61; PERRONE-MOISÉS, 1992, p. 119).

De acordo com a petição apresentada pelo interessado e reproduzida no corpo do próprio alvará, o mesmo havia se dedicado durante nove anos a fazer descer "do sertão para as suas fazendas e terras de Itapororocas e Jacuipe o gentio da nação Payayá, em defença do gentio brabo [sic] que desce ás aldeias muitas vezes, a roubar e matar a sua gente como matou dezessete escravos, roubou sete fazendas e queimou cinco". O sertanista, com a ajuda dos referidos índios, teria segurado e protegido "os muitos moradores dos Campos da Cachoeira" que queriam despovoar a região, numa extensão de mais de vinte léguas, por temerem os ataques dos "bárbaros". João Peixoto Viegas, como bom vassalo, teria enfrentado o inimigo "com manifesto perigo de sua vida e família e grande despeza", tendo como 
aliados os Payayá que sempre o ajudavam nas guerras, como também aos governadores, reconhecendo e afirmando que

[...] os ditos Índios Paiyaayás forão valentes e leaes e os que mais trabalharão como a Vossa Senhoria he presente, sem nunca fugirem, nem faltar algum por o supplicante assim lhe o encommendar e fazer entender sua obrigação no serviço de Sua Alteza, e obediencia de Vossa Senhoria pelo dito João Peixoto Viegas ter muito domesticado e afeiçoado com continuos benefícios (SILVA, 1925, p. 231-232, grifo nosso).

Seguiu-se, então, um embate entre Peixoto Viegas e os padres da Companhia de Jesus em torno da administração dos Payayá (Cf. ARAÚJO, 2015, p. 81-96). O primeiro, favorecido pelo provedor-mor António Lopes de Ulhoa e pela Junta Governativa (1675-1678) que sucedeu a Rio de Mendonça e da qual fazia parte o também sertanista Antonio Guedes de Brito. O novo governador Roque da Costa Barreto (1678-1682), no entanto, foi favorável aos jesuítas e os Payayá acabaram sendo "descidos" para os aldeamentos de Serinhaem (São Miguel e Santo André) em Camamu, como mencionado anteriormente (Cf. LEITE, 2000, p. 279-80; CALDAS, 1951, p. 54).

Para além deste embate em nível local, os jesuítas - como de costume - levaram a questão até a Corte, onde conseguiram, mediante uma provisão emitida por el-Rei, a confirmação da sua prerrogativa de administradores dos índios aldeados na colônia, com a garantia "de se reporem [aos religiosos] todos os índios das Aldeias por João Peixoto Viegas e Antonio Guedes de Brito ou por qualquer outro secular". O monarca, em vista das leis existentes e em consideração "à boa direcção e forma com que os Padres da Companhia domesticam e doutrinam os índios", houve por bem

[...] lhes conceder a ordem espiritual e temporal, porém com tal condição que quando forem necessários para meu serviço os não escondam e neguem como se verifica que o fizeram em alguma occasião e neste particular cumpram e guardem as ordens dos Governadores e as que lhes passarem para a repartição delles quando forem necessários aos moradores, e também com condição que os Padres continuem as Missões em o sertão como antigamente faziam e nelle formem Aldeias e Igrejas em que doutrinem os índios e lhes administrem os Sacramentos por este ser o intento das Missões e minha obrigação pelo que mando ao Mestre de Campo General do Estado do Brasil a cujo cargo está o Governo delle (DOCUMENTOS HISTÓRICOS, 29, p. 117-119).

Mostra-se evidente que a política iniciada pelos inacianos, de criar aldeamentos fixando grupos indígenas em espaços reduzidos para catequizá-los e discipliná-los, obteve o apoio da Coroa, principalmente porque possibilitou a consolidação de diversas vilas e povoações coloniais. Por outro lado, a busca pelas reais ou supostas riquezas escondidas no sertão e a política de deslocamento de grupos indígenas para regiões próximas aos núcleos coloniais favoreceu a interiorização do movimento colonizador e a ocupação das terras sertanejas, incluindo o sertão das Jacobinas, constituindo elemento de tensão permanente entre o projeto colonial e o catequético (cf. SANTOS, S., 2011; POMPA, 2003; SANTOS, F., 2014). 


\section{CONSIDERAÇÕES FINAIS}

É inegável a importância que tiveram os jesuítas enquanto elementos essenciais do avanço colonial mediante a formação de uma barreira de aldeias de índios "mansos" e o controle dos "tapuias" pacificados (POMPA, 2003, p. 319). No entanto, como visto acima, não se deve subestimar o papel dos sertanistas, como Peixoto Viegas e Guedes de Brito, que também atuaram junto a determinados grupos indígenas para fazer frente aos ataques dos considerados "bárbaros" e "inimigos". Envolvidos em tais disputas, os indígens aparecem nas entrelinhas da documentação como agentes históricos conscientes das vantagens e desvantagens propiciadas em cada situação e vendendo caro sua colaboração. Não por acaso, Peixoto Viegas, para os manter "domesticados e afeiçoados", lhes oferecia, em troca, "contínuos benefícios" (SILVA, 1925, p. 231).

Os Payayá das Jacobinas - como os demais povos indígenas das Américas - buscaram o tempo todo estratégias de sobrevivência, alternando a resistência com a colaboração em suas relações de contato e enfrentamento dos agentes coloniais. Ao lado de outros povos que aparecem na documentação consultada, produzida ao longo da conquista dos sertões baianos,, como os Sapoiás, Moritises, Maracás, Topins, Xocós e Anaiós, e diante da imposição do domínio político, da ocupação de suas terras pelos colonos e missionários, da prática catequética, do confinamento, da desestruturação socioeconômica, do trabalho compulsório e da escravidão mal disfarçada, restou como opção continuar lutando - até os dias atuais - em busca de respostas e perspectivas de futuro diante da dura realidade colonialista (PARAÍSO, 2016).

\section{FONTES}

ANTONIL, A. J. Cultura e Opulência do Brasil. $3^{\circ}$ ed. Belo Horizonte: Itatiaia; São Paulo: Ed. da USP, 1982.

CALDAS, J. A. Noticia Geral de toda esta Capitania da Babia desde o seu Descobrimento até o Presente Ano de 1759. Ed. fac-similar. Salvador: Tipografia Beneditina, 1951.

DOCUMENTOS HISTÓRICOS. Biblioteca Nacional do Rio de Janeiro. 1928-1955.

GÂNDAVO, P. de M. Tratado da Terra do Brasil: História da Provincia Santa Cruz. (séc. XVI). Belo Horizonte: Itatiaia; São Paulo: Ed.da USP, 1980.

LEAL, P. B. (Cel). Relatório ao Vice-rei Conde de Sabugosa sobre os itinerários de Gabriel Soares de Sousa e Belchior Dias Moreira, de 22 de novembro de 1725. In: VARNHAGEN, F. A. História Geral do Brasil. Tomo II, v. I. $10^{a}$ ed. São Paulo: Melhoramentos, 1978.

PITTA, S. da R. História da América Portuguesa. Anotações de Pedro Calmon. São Paulo: Editora Brasileira, 1965. 
SALVADOR, V. História do Brazil. Rio de Janeiro: Publicação da Bibliotheca Nacional; TYP. de G. Leuzinger \& Filhos, 1889.

SILVA, I. A. C. Memórias históricas e politicas da Provincia da Babia. v. 2. Anotações de Braz do Amaral. Bahia: Imprensa Oficial do Estado, 1925.

SOUSA, G. S. Tratado descritivo do Brasil em 1587. Belo Horizonte: Itatiaia, 2001.

VASCONCELOS, S. Crônica da Companbia de Jesus. v. I. $3^{\text {a }}$ ed. Petrópolis: Vozes; Brasilia: INL, 1977

VILHENA, L. dos S. A Babia do Século XVIII. Notas e comentários de Braz do Amaral. Salvador: Itapuã, 1968.

\section{REFERÊNCIAS}

ARAÚJO, A. T. Catequização, colonização e conflitos na sesmaria de João Peixoto Viegas na Babia, 1653-1700. Dissertação (Mestrado em História Regional e Local) - Universidade do Estado da Bahia, Santo Antônio de Jesus, 2015.

COSTA, A. Jacobina Minha Terra, de antanho e de agora. In: Annaes do $5^{\circ}$ Congresso Brazileiro de Geographia realizado em 1916. v. II. Bahia: Imprensa Official do Estado; Instituto Geographico e Histórico da Bahia, 1918.

DANTAS, B. G., SAMPAIO, J. A. L., CARVALHO, M. R. G. Os povos indígenas no Nordeste brasileiro: um esboço histórico. In: CUNHA, M. C. (org.). História dos indios no Brasil. São Paulo: Companhia das Letras, 1992.

ETCHEVARNE, C. (org.). Inventário de locais com vestigios arqueológicos do município de Morro do Chapéu, Babia. Salvador: IPAC; Fundo de Cultura, 2015.

FALCÃO, M. F. P. Pequeno Dicionário Toponímico da Babia. Fortaleza: Gráfica Santa Helena, 2001.

LEITE, S. História da Companbia de Jesus no Brasil.. Edição Fac-símile Comemorativa. Belo Horizonte: Itatiaia, $2000.10 \mathrm{v}$

LEITE, S. (org.). Novas cartas jesuiticas (de Nóbrega a Vieira). São Paulo: Companhia Editora Nacional, 1940.

MAgALHÃES, A. P. M. Para a conquista dos bárbaros: rede de poder e governação de Afonso Furtado de Castro do Rio Mendonça (1671-1675). Dissertação (Mestrado em História Regional e Local) Universidade do Estado da Bahia, Santo Antônio de Jesus, 2015.

MIGUEL, A.; NEVES, E. (org). Caminhos do sertão: ocupação territorial, sistema viário e intercâmbios coloniais. Salvador: Arcadia, 2007.

NEVES, J. B. Colonização e resistência no Paraguaçu - Babia, 1530-1678. Dissertação (Mestrado em História) - Faculdade de Filosofia e Ciências Humanas, Universidade Federal da Bahia, Salvador, 2008.

OTT, C. As culturas pré-históricas da Babia: a cultura material. Salvador: Bigraf, 1993. 
O'T'T, C. Os elementos culturais da pescaria baiana. Boletim do Museu Nacional. Rio de Janeiro, n 4., 30 out. 1944.

PARAÍSO, M. H. B. Índios na atualidade: uma realidade de perdas e ganhos. In: SANTOS, F. L. (org.). Os índios na História da Babia. Cruz das Almas: Ed. da UFRB; Belo Horizonte: Fino Traço, 2016. p. 125137.

PERRONE-MOISÉS, B. Índios livres e índios escravos: Os princípios da legislação indigenista do período colonial (séculos XVI a XVIII). In: CUNHA, M. C. (org.). História dos Índios no Brasil. São Paulo: Companhia das Letras, 1992. p. 115-132.

POMPA, C. Religião como tradução: missionários, Tupi e Tapuia no Brasil colonial. Bauru: EDUSC; ANPOCS, 2003.

PUNTONI, P. A Guerra dos Bárbaros: povos indígenas e a colonização do sertão. Nordeste do Brasil, 1650-1720. São Paulo: Hucitec; Edusp; Fapesp, 2002.

SAMPAIO, T. O Tupi na Geographia Nacional. Memória lida no Instituto Histórico e Geographico de São Paulo. São Paulo: Typ. da Casa Eclectica, 1901.

SANTOS, F. L. Da catequese à civilização: colonização e povos indígenas na Bahia. Cruz das Almas: Ed. da UFRB, 2014.

SANTOS, S. N. A. Conquista e Resistência dos Payayá no Sertão das Jacobinas: tapuia, tupi, colonos e missionários (1651-1706). Dissertação (Mestrado. em História) - Faculdade de Filosofia e Ciências Humanas, Universidade Federal da Bahia, Salvador, 2011.

VAINFAS, R. A heresia dos Índios. Catolicismo e rebeldia no Brasil Colonial. São Paulo: Companhia das Letras, 1995.

Data de submissão: 01/10/2020

Data de aprovação: $13 / 11 / 2020$ 